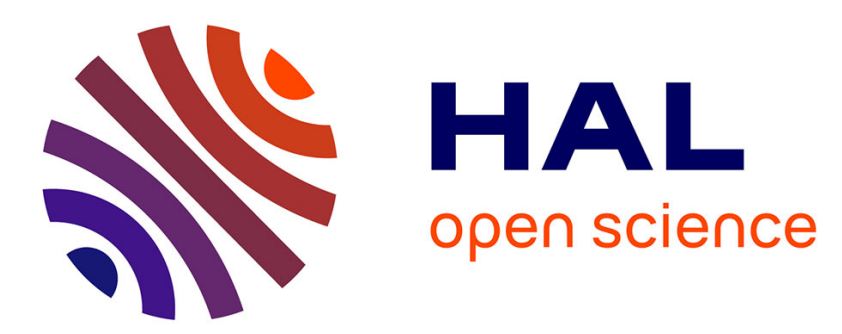

\title{
Experimental and numerical assessment of subsurface plastic deformation induced by OFHC copper machining
} José Outeiro, Sébastien Campocasso, Lamice Denguir, Guillaume Fromentin, Vincent Vignal, Gérard Poulachon

\section{- To cite this version:}

José Outeiro, Sébastien Campocasso, Lamice Denguir, Guillaume Fromentin, Vincent Vignal, et al.. Experimental and numerical assessment of subsurface plastic deformation induced by OFHC copper machining. CIRP Annals - Manufacturing Technology, 2015, 64 (1), pp.53-56. 10.1016/j.cirp.2015.04.080 . hal-01178081

\section{HAL Id: hal-01178081 \\ https://hal.science/hal-01178081}

Submitted on 17 Jul 2015

HAL is a multi-disciplinary open access archive for the deposit and dissemination of scientific research documents, whether they are published or not. The documents may come from teaching and research institutions in France or abroad, or from public or private research centers.
L'archive ouverte pluridisciplinaire HAL, est destinée au dépôt et à la diffusion de documents scientifiques de niveau recherche, publiés ou non, émanant des établissements d'enseignement et de recherche français ou étrangers, des laboratoires publics ou privés. 


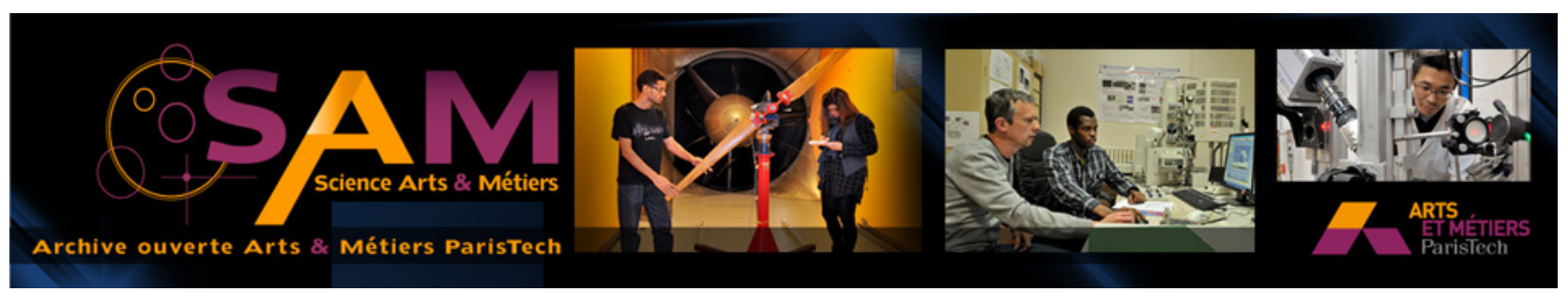

\section{Science Arts \& Métiers (SAM)}

is an open access repository that collects the work of Arts et Métiers ParisTech researchers and makes it freely available over the web where possible.

This is an author-deposited version published in: http://sam.ensam.eu

Handle ID: .http://hdl.handle.net/10985/9808

\section{To cite this version :}

José OUTEIRO, Sébastien CAMPOCASSO, Lamice DENGUIR, Guillaume FROMENTIN, Vincent VIGNAL, Gérard POULACHON - Experimental and numerical assessment of subsurface plastic deformation induced by OFHC copper machining - CIRP Annals - Manufacturing Technology Vol. $64, n^{\circ} 1$, p.53-56-2015 


\title{
Experimental and numerical assessment of subsurface plastic deformation induced by OFHC copper machining
}

\author{
J.C. Outeiro $(2)^{\mathrm{a}, *}$, S. Campocasso ${ }^{\mathrm{a}, \mathrm{b}}$, L.A. Denguir ${ }^{\mathrm{a}, \mathrm{c}}$, G. Fromentin ${ }^{\mathrm{a}}$, V. Vignal ${ }^{\mathrm{c}, \mathrm{d}}$, \\ G. Poulachon $(2)^{\mathrm{a}}$ \\ ${ }^{a}$ Arts et Metiers ParisTech, LaBoMaP, Rue Porte de Paris, 71250 Cluny, France \\ ${ }^{\mathrm{b}}$ CEA, DAM, Valduc, 21120 Is-sur-Tille, France \\ ' $I C B$, UMR 6303 CNRS - Université de Bourgogne, BP 47870, 21078 Dijon, France \\ ${ }^{\mathrm{d}}$ Laboratoire Interactions Matériau-Procédé-Environnement, LRC LIMPE n DAM-VA-11-02, France
}

A R T I C L E I N F O

Keywords:

Machining

Deformation

Finite element method (FEM)

\begin{abstract}
A B S T R A C T
Strain distributions in the machined surface and subsurface of OFHC copper workpieces were determined experimentally and through numerical simulations. An experimental setup, comprising a double frame camera and a pulsed laser, was developed to measure the displacement fields using the digital image correlation (DIC) technique; strain distributions were then calculated. A numerical orthogonal cutting model was also developed and applied in order to predict such distributions. Comparison between simulated and measured results enabled an understanding of the fundamental mechanisms of plastic deformation of the machined surface of OFHC copper.
\end{abstract}

\section{Introduction}

Residual stress and plastic strain distributions in the machined surface and subsurface are two key surface integrity parameters used to evaluate the functional performance and life of components [1]. Traditionally, much attention is paid to the experimental measurement (quantification) of residual stresses in machined components, which is confirmed by the large number of scientific publications on residual stress distributions for a wide range of work materials and cutting conditions (including tool geometry, tool material and cooling conditions). So far, less attention has been paid to the plastic strain distribution in the machined surface and subsurface of components, which is mainly due to the lack of scientific techniques suitable for measuring (quantifying) such plastic strains. However, the rapid rise of new techniques based on high-speed/high-resolution imaging devices opens new possibilities for analysing not only the plastic strain but also the strain-rate distributions generated in metal cutting. This information is very useful for validating metal-cutting numerical models and to understand the fundamental mechanisms of the plastic deformation of machined surfaces [2].

High-speed/high-resolution imaging techniques, such as the Digital Imaging Correlation (DIC) and Particle Image Velocimetry (PIV), are commonly used to measure the strain and strain-rate fields generated in the chip formation process (primary and secondary deformation zones) [3]. However, increased requirements in terms

\footnotetext{
* Corresponding author.

E-mail address: jose.OUTEIRO@ensam.eu (J.C. Outeiro).
}

of the complete characterisation of the machined surface integrity have led to the application of such techniques to the analysis of the residual plastic strain distribution in the machined surface and subsurface, too. One example is the work performed by Guo et al. [4], where the DIC technique was applied to study the deformation history of the machined surface of brass and Oxygen Free High Conductivity (OFHC) copper. It is worth noting that an extremely low cutting speed $(0.6 \mathrm{~m} / \mathrm{min})$ was used when compared to suitable cutting speeds for machining this work material (around $120 \mathrm{~m} /$ min). A conclusion of this study was that the magnitude of equivalent plastic strain in the machined surface is identical to that observed in the chip.

In this paper, residual plastic strain distributions in the machined surface and subsurface, induced by the orthogonal cutting of OFHC copper under practical machining conditions (including high cutting speeds), were investigated using both numerical modelling and experimental DIC techniques, including a similar imaging device to that used by Hijazi and Madhavan [5]. The numerical results were finally compared to those obtained experimentally in terms of forces, chip compression ratio, residual plastic strain and hardness distributions.

\section{Experimental and numerical procedures}

\subsection{Work material, cutting tools and cutting parameters}

Orthogonal cutting tests on flat specimens of OFHC copper (annealed, average grain size of $50 \mu \mathrm{m}$ and average hardness of $46 \mathrm{HB}$ ) with a size of $40(L) \mathrm{mm} \times 15(H) \mathrm{mm} \times 4(W) \mathrm{mm}$ were performed in planing configuration. The uncoated cemented 
tungsten carbide cutting tools had an edge radius $\left(r_{n}\right)$ of $8 \pm 2 \mu \mathrm{m}$, a flank angle $(\alpha)$ of $10^{\circ}$ and two rake angle values $\left(\gamma=20^{\circ}\right.$ and $\left.30^{\circ}\right)$. To minimise lateral burr formation and its consequences on strain distribution, a weak inclination angle $\left(\lambda_{s}\right)$ of $2^{\circ}$ was used in the experiments. The cutting speed $\left(v_{c}\right)$ and width of cut $\left(a_{p}\right)$ were maintained constant, equal to $90 \mathrm{~m} / \mathrm{min}$ and $4 \mathrm{~mm}\left(a_{p}=W\right)$, respectively. In order to evaluate the influence of cutting conditions on the strain distributions induced in the machined subsurface, three values of uncut chip thickness $(h)$ were used $(0.05,0.1$ and $0.2 \mathrm{~mm})$. The combination of these $h$ and $\gamma$ values enabled us to vary the severity of the cutting process and its consequences on strain distribution. Low temperature pressurised air $\left(3 \pm 2{ }^{\circ} \mathrm{C}, 6\right.$ bar $)$ was applied to minimise the adhesion phenomenon between the tool and the work material. For each set of cutting conditions, five tests were performed.

\subsection{Experimental set-up and parameters}

The above-mentioned orthogonal cutting tests using a planing configuration were performed on a DMG DMC85V milling machine (linear motor drive system), equipped with a specially-designed experimental set-up for measuring the displacement fields on the lateral specimen faces during cutting. The cutting speed was applied to the tool (attached to the milling head), while the workpiece was maintained static (attached to the milling table). A LaVision Imager sCMOS double-frame camera $(2560 \times 2160$ pixel sensor with a dynamic range of 16 bits) and a Litron NS30-15 (Nd:YAG) dual-pulsed laser were used to capture the images used afterwards for the Digital Image Correlation (DIC). Using a Mitutoyo ML $10 \times$ telecentric lens, the field of view size was $1.7 \mathrm{~mm} \times 1.4 \mathrm{~mm}$, with a resolution of $0.66 \mu \mathrm{m} /$ pixel. This equipment enables image pairs to be captured with a frequency of $15 \mathrm{~Hz}$, precluding any continuous acquisition during cutting. Therefore four image pairs (denoted P0, P1, P2 and P3) were acquired for each test. Each pair contains two frames (f0 and f1), with an inter-frame time of $15 \mu$ s. The acquisition procedure was based on the following:

- Two pairs before the cutting test, denoted P0\{f0, f1 $\}$ and P1\{f0, f1\}, allowing measurement uncertainties to be evaluated.

- One pair during the cutting test, denoted P2\{f0, f1\}, enabling the chip formation to be analysed.

- One pair after the end of the cutting test, denoted P3\{f0, f1\}.

When DIC is performed between images $\mathrm{P} 1 \mathrm{f} 0$ and $\mathrm{P} 2 \mathrm{fO}$, the total strains induced by cutting can be measured. However, the objective of the present research is to determine the residual plastic strains in the workpiece after cutting. Therefore, DIC was performed between images P1f0 and P3f0. The displacement fields were measured using Correli ${ }^{\mathrm{Q} 4}$ software [6], with an uncertainty of around $0.16 \mu \mathrm{m}$ (evaluated by DIC calculations performed using images POf0 and P1f0), or $8 \times 10^{-3}$ in strain for an element size of 32 pixels. Then the residual plastic strain components $\left(\varepsilon_{x x}, \varepsilon_{y y}, \varepsilon_{x y}\right.$ and $\varepsilon_{y x}$ ) and the equivalent (von Mises) residual plastic strain $\left(\varepsilon_{e q}\right)$ distributions were calculated. A Kistler 9119AA2 dynamometer, with a 5019A charge amplifier, was also used to measure the forces.

Before the orthogonal cutting tests, the lateral specimen faces under observation by the camera were blasted with glass microbeads, and all the specimens were annealed $\left(450{ }^{\circ} \mathrm{C}\right.$ during $\left.2 \mathrm{~h}\right)$. As a consequence, a surface roughness suitable for DIC was obtained corresponding to $S_{a}, S_{p d}$ and $S_{p c}$ equal to $2.24 \mu \mathrm{m}, 401$ peaks $/ \mathrm{mm}^{2}$ and $358 \mathrm{~mm}^{-1}$, respectively. These parameters were measured using a Veeco Wyko NT1100 interferometer.

\subsection{Numerical models and parameters}

A numerical model based on the Arbitrary Lagrangian-Eulerian (ALE) formulation was developed and applied to simulate the surface and subsurface plastic deformation, induced by orthogonal cutting process of OFHC copper. The commercial FEA software ABAQUS/Explicit and a plane-strain mechanical analysis were used. To model the viscoplastic behaviour of OFHC copper, the Johnson-Cook constitutive model was employed [7], which is represented by Eq. (1), where $\bar{\sigma}$ is the equivalent stress (MPa), $\bar{\varepsilon}$ is the equivalent plastic strain, $\dot{\bar{\varepsilon}}$ is the equivalent plastic strain rate $\left(\mathrm{s}^{-1}\right), \dot{\bar{\varepsilon}}_{0}$ is the reference equivalent plastic strain rate $\left(0.01 \mathrm{~s}^{-1}\right), T$ is the temperature $\left({ }^{\circ} \mathrm{C}\right), T_{m}$ is the melting temperature of the work material $\left(1083^{\circ} \mathrm{C}\right)$ and $T_{\text {room }}$ is the room temperature $\left(20^{\circ} \mathrm{C}\right) . A, B$, $C, n$ and $m$ are material parameters, which were obtained from experimental quasi-static and dynamic compression tests at different strain rates and temperatures. They are equal to $90 \mathrm{MPa}, 500 \mathrm{MPa}, 0.022,0.52$ and 0.83 , respectively.

$$
\bar{\sigma}=\underbrace{\left(A+B \bar{\varepsilon}^{n}\right)}_{\text {Strain hardening effect }} \underbrace{\left[1+C \ln \left(\frac{\dot{\bar{\varepsilon}}}{\dot{\overline{\bar{\varepsilon}}}}\right)\right]}_{\text {Strain-rate(viscosity) effect }} \underbrace{\left[1-\left(\frac{T-T_{\text {room }}}{T_{m}-T_{\text {room }}}\right)^{m}\right]}_{\text {Thermal softening effect }}
$$

The elastic and thermal properties of the work material were obtained from experimental tests on the same work material as that used in the machining tests. The tool was modelled as elastic, its thermal and elastic properties being obtained from literature [8]. Concerning the tribological characteristics of the tool-chip and tool-workpiece interfaces, Zorev's model was used [9]. The value of the friction coefficient was determined from tribological tests described in [10]. These tests enabled the determination of the apparent friction coefficient $\left(\mu_{a p p}\right)$, which includes both contributions of interfacial (local) adhesive phenomena $\left(\mu_{\text {adh }}\right)$ and macroscopic plastic deformation $\left(\mu_{\text {plast }}\right)$. For the numerical simulation, $\mu_{\text {adh }}$ should be used; for the range of sliding velocities and contact pressures applied in the machining tests, this coefficient can be represented as a function of the sliding velocity $\left(v_{s}\right)$, given by the following equation:

$\mu_{\text {adh }}=c_{1}+\frac{c_{2}}{1+\left[\left(v_{s}-c_{3}\right) / c_{4}\right]^{2}}$

where the coefficients $c_{i}(i=1, \ldots, 4)$ are equal to $0.787,0.185$, 0.764 and 0.362 , respectively. It is worth noting that the proposed equation follows the general trend of the friction coefficient with respect to the sliding velocity found by Zorev [9]. Concerning the limit shear stress $\left(\tau_{\text {limit }}\right)$, this is equal to the yield shear stress $\left(\tau_{y}=\sigma_{y} / \sqrt{3}\right)$ and was calculated based on the estimated yield stress $\left(\sigma_{y}\right)$ of the deformed superficial layers of the chip and machined surface. This estimation was based on the relation between the Vickers hardness (HV) and the yield stress $\left(\sigma_{y}\right)$, which was proposed by Krishna et al. [11] and given by the following equation:

$\sigma_{y}=1.97 \cdot \mathrm{HV}$

\section{Results and discussion}

\subsection{Chip compression ratio and cutting force}

Chip compression ratio (CCR) is a quantitative measurement of the total plastic deformation reached in the cutting process and is usually given by the ratio between the chip thickness $\left(h_{c h}\right)$ and $h$ [12]. However, due to the irregular chip thickness and slightly larger chip width when compared to the width of cut, the CCR was calculated by dividing the chip cross-section by the uncut chip cross-section. Fig. 1a shows both the measured and predicted $C C R$ for two rake angles and two uncut chip thickness values. For the same cutting conditions, the CCR predicted by the ALE model is similar to that measured, except for $\gamma$ being equal to $20^{\circ}$ and $h$ equal to $0.05 \mathrm{~mm}$. Moreover, for the range of $\gamma$ and $h$ used in this study, the most important parameter affecting the CCR is $\gamma$. Therefore, it is expected that the deformation in the machined surface will be more intense and will affect deeper material layers as $\gamma$ is decreased. 


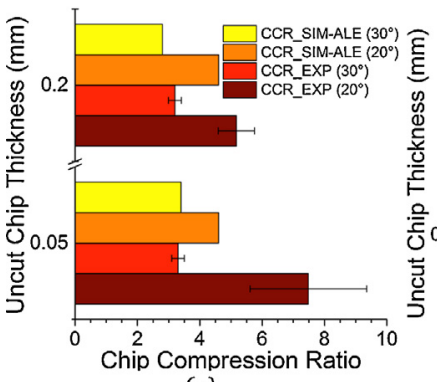

(a)

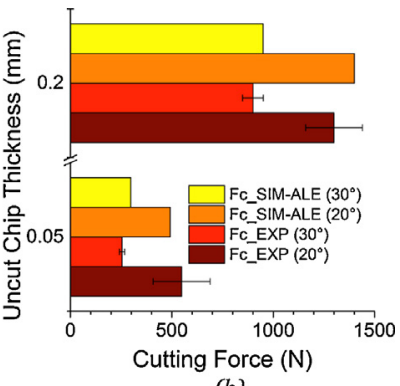

(b)
Fig. 1. Measured and predicted (a) $C C R$ and (b) cutting force $\left(F_{c}\right)$ as a function of the tool rake angle and uncut chip thickness.

The cutting force applied to the cutting tool was also experimentally measured and numerically predicted. Fig. 1b shows both measured and predicted cutting force $\left(F_{c}\right)$ for two rake angles and two uncut chip thickness values. For the same cutting conditions, the $F_{c}$ predicted by the ALE model is similar to that measured. $F_{c}$ increases as $\gamma$ is decreased and as $h$ is increased, with the other cutting conditions remaining constant.

Although the ALE model predicts the cutting forces and CCR reasonably well, for a complete validation of this model a comparison between predicted and measured machined surface integrity features (including plastic deformation) is required.

\subsection{Residual plastic strain distribution in the machined surface and subsurface}

Fig. 2 shows an example of $\varepsilon_{e q}$ distribution in the machined subsurface, calculated from the residual plastic strain components, assuming plane strain conditions [12]. For the range of cutting conditions used in this study, it was not possible to obtain the plastic strain distribution in a layer closer to the surface without an excessive distortion of the global DIC technique mesh, induced by the high strain values. Depending on the cutting conditions, the thickness of this layer varied from 40 to $300 \mu \mathrm{m}$.

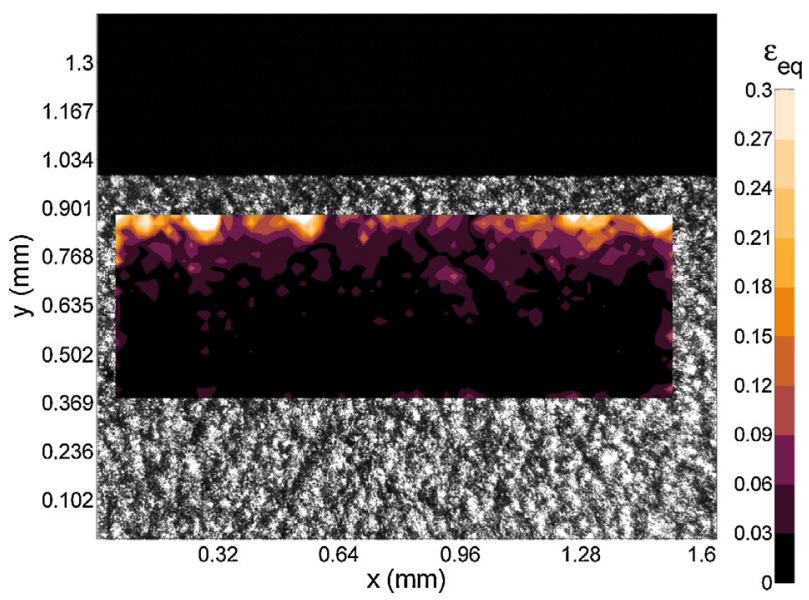

Fig. 2. Subsurface distribution of the equivalent residual plastic strain for $\gamma=30$ and $h=0.1 \mathrm{~mm}$.

From these strain distributions, in-depth profiles were calculated by averaging the strains for each subsurface layer. Fig. 3 shows an example of the in-depth profiles of the plastic strains obtained experimentally and by numerical simulation. This figure shows a good qualitative agreement between measured and predicted results. In particular, the predicted in-depth strain profiles follow the general trend of those measured for depths greater than $100 \mu \mathrm{m}$. This figure also shows that the shear strain component $\left(\varepsilon_{x y}\right)$ is much higher than the others, suggesting that shear is the principal deformation mode of the machined surface. Moreover, since for the range of cutting conditions investigated the

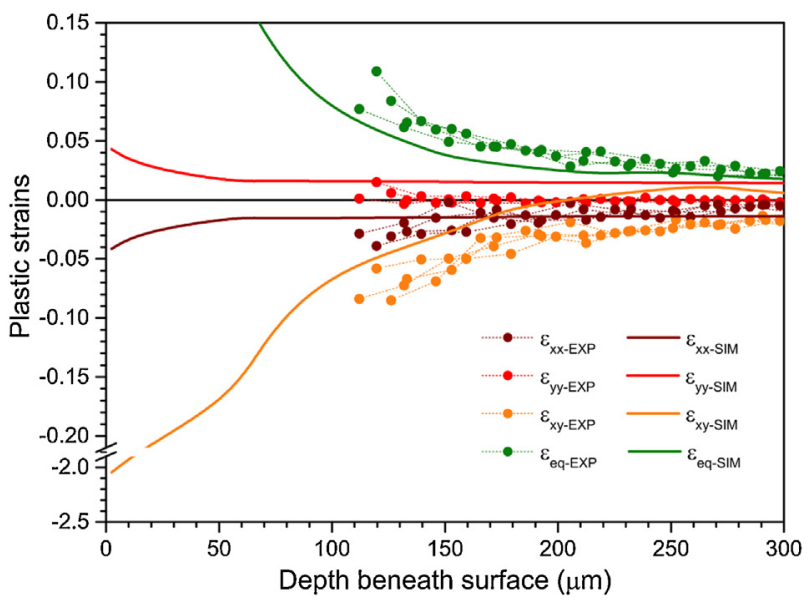

Fig. 3. In-depth profiles of the plastic strain components for $\gamma=30^{\circ}$ and $h=0.1 \mathrm{~mm}$.

shear strain component $\varepsilon_{y x}$ is zero and the normal strain components are very low $\left(\varepsilon_{x x}\right.$ and $\left.\varepsilon_{y y}\right)$, the predominant deformation mode seems to be simple shear.

Fig. 4 shows both predicted and measured in-depth profiles of $\varepsilon_{e q}$ for $\gamma$ equal to $30^{\circ}$ and $h$ varying from 0.05 to $0.2 \mathrm{~mm}$. Although experimentally no strain distribution is known closer to the surface, the predicted in-depth profiles of $\varepsilon_{e q}$ capture quite well the in-depth evolution of the measured $\varepsilon_{e q}$, for depths higher than $100 \mu \mathrm{m}$. Indeed, these predicted in-depth profiles of $\varepsilon_{e q}$ pass through the lower boundary of each plastic strain domain, which corresponds to a given value of $h$. As also shown in this figure, the magnitude of $\varepsilon_{e q}$ and the thickness of the deformed layer increase with $h$. At the surface, the equivalent plastic strains predicted by the ALE numerical model can reach values of around 2 to 3 , depending on the cutting conditions, and they also increase with $h$. The predicted high plastic strain values at the machined surface support the hypothesis of the severe plastic deformation (SPD) of the machined surface. Although this hypothesis cannot be verified using the present DIC technique, the plastic strains found experimentally by Guo et al. [4] for the same work material and similar cutting conditions (except the cutting speed), are similar to those predicted using the present ALE numerical model.

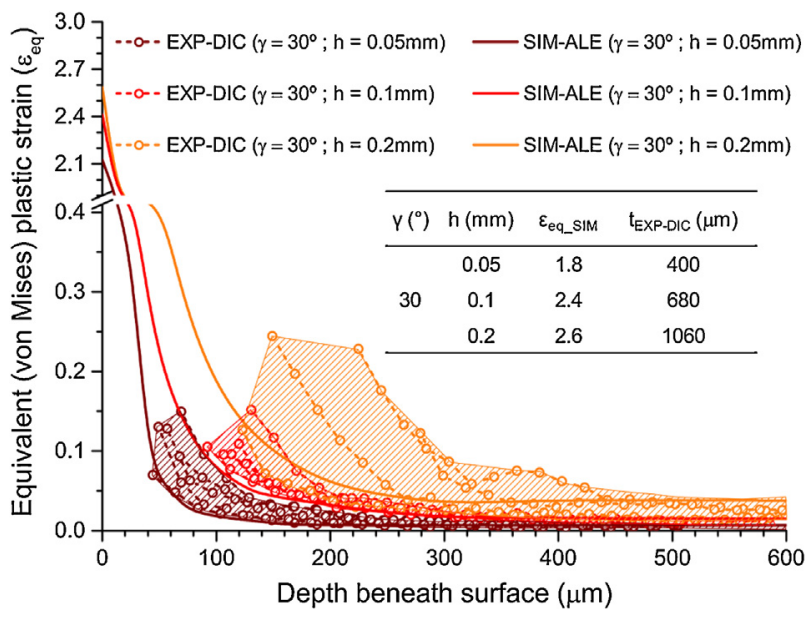

Fig. 4. Measured and predicted in-depth plastic strain distributions with respect to the uncut chip thickness.

Fig. 5 shows the same measured in-depth profiles of $\varepsilon_{e q}$ represented in Fig. 4, but with respect to the normalised depth, which was obtained by dividing the depth $(d)$ by $h$. The dots shown in Fig. 5 represent the experimental $\varepsilon_{e q}$ values for each level of $h$, while the black line represents a fitting curve for all the data, obtained using the equation detailed in the figure. This means that for the same cutting conditions but for a different $h$, the $\varepsilon_{e q}$ 


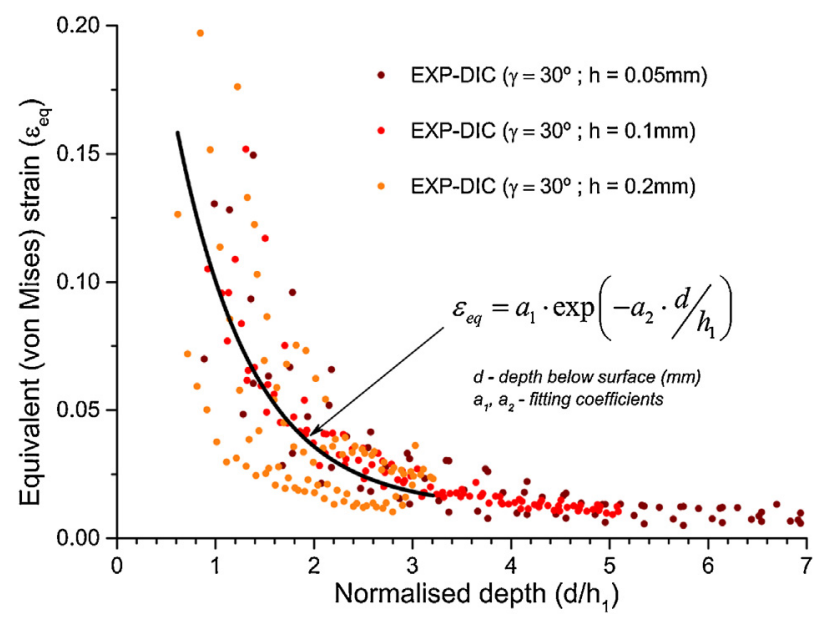

Fig. 5. Equivalent plastic strain with respect to the normalised depth.

distribution is controlled by the non-dimensional parameter, $d /$ $h$. Identical results were also obtained by Guo et al. [4] at a very low cutting speed $(0.6 \mathrm{~m} / \mathrm{min})$.

As far as the influence of $\gamma$ is concerned, Fig. 6 shows both predicted and measured in-depth profiles of $\varepsilon_{e q}$ for $h$ equal to $0.05 \mathrm{~mm}$ and $\gamma$ varying from $20^{\circ}$ to $30^{\circ}$. As shown in this figure, $\varepsilon_{e q}$ increases as $\gamma$ is decreased from $30^{\circ}$ to $20^{\circ}$. At the surface, the equivalent plastic strains predicted by the ALE numerical model can reach values of around 3.4 for the severest cutting conditions (lowest $\gamma=20^{\circ}$, and highest $h=0.2 \mathrm{~mm}$ ), which confirms the severity of the plastic deformation of the machined surface.

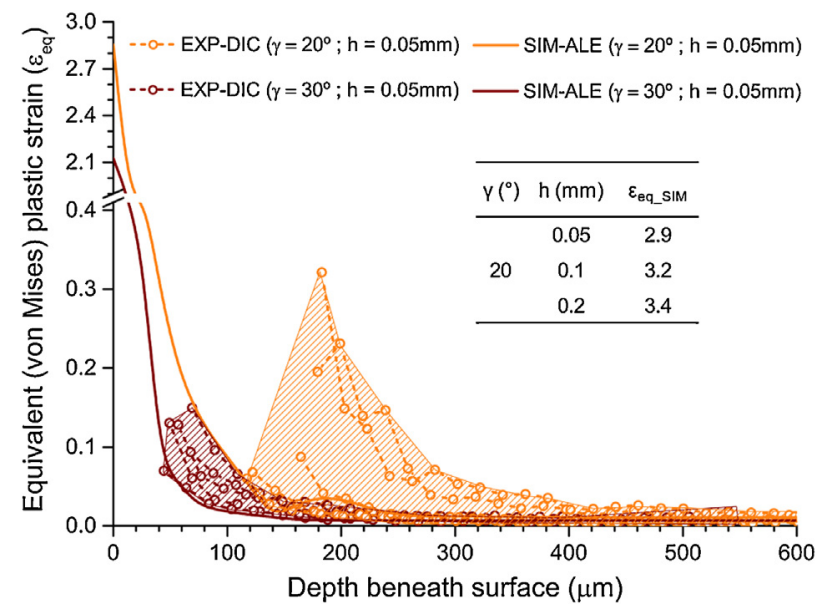

Fig. 6. Measured and predicted in-depth plastic strain distributions as a function of the rake angle.

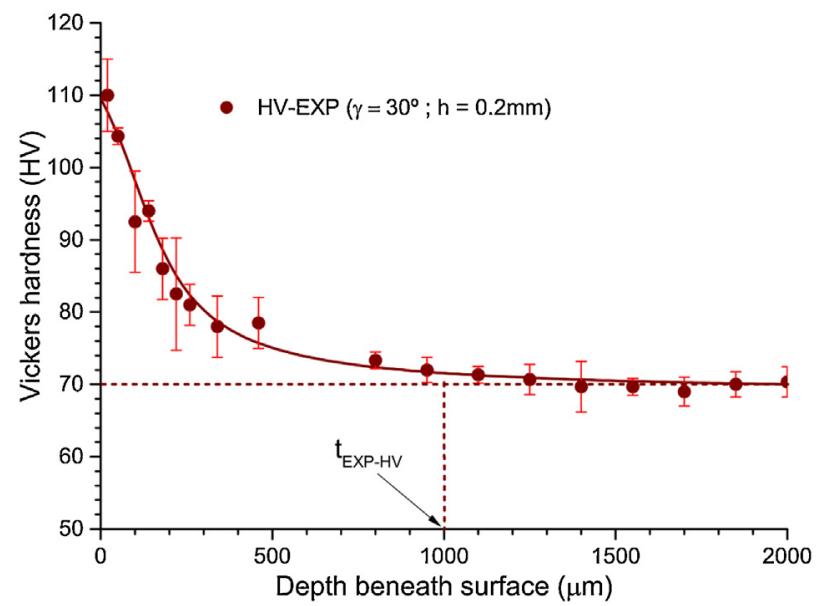

Fig. 7. Measured in-depth Vickers micro-hardness distribution in the machined surface.
In order to compare the thickness of the deformed layer measured by DIC with that measured using another technique, micro-hardness measurements were also performed. Fig. 7 shows an in-depth profile of Vickers micro-hardness for $\gamma$ equal to $30^{\circ}$ and $h$ equal to $0.2 \mathrm{~mm}$. The hardness is greater at the machined surface, reaching $110 \pm 5 \mathrm{HV}$, and decreases as the depth is increased, stabilising around a value of $70 \pm 4 \mathrm{HV}$. Since hardness is related to strain hardening, this means that strains should follow the same variations as hardness. Therefore, depending on the hardness measurement, the thickness of the deformed layer ( $\left.t_{\mathrm{EXP}-\mathrm{HV}}\right)$ is in this case about $1000 \mu \mathrm{m}$. As shown in Fig. 4, a similar value was also obtained using the DIC technique, which means that this technique captures the plastic deformation field quite well.

\section{Conclusions and outlook}

A DIC experimental technique and numerical modelling were applied to evaluate the residual plastic strain distribution in the machined surface and subsurface of OFHC copper, machined at practical cutting speeds. The predicted equivalent plastic strain is higher at the machined surface, reaching values between 1.8 and 3.4 , which confirms the severe plastic deformation of the machined surface. Moreover, based on the distribution of the plastic strain components, the predominant deformation mode seems to be simple shear. Both the plastic strain and the thickness of the deformed layer increase when the uncut chip thickness increases and when the rake angle decreases.

Although the DIC technique requires only two images to capture the plastic deformation with good accuracy, further improvements are required in order to determine the strains closer to the surface.

\section{Acknowledgments}

The authors would like to thank Rémy Besnard and Thomas Baizeau for their help on implementing the DIC technique.

\section{Appendix A. Supplementary data}

Supplementary data associated with this article can be found, in the online version, at doi:10.1016/j.cirp.2015.04.080.

\section{References}

[1] Jawahir IS, Brinksmeier E, M'Saoubi R, Aspinwall DK, Outeiro JC, et al (2011) Surface Integrity in Material Removal Processes: Recent Advances. CIRP Annals 60(2):603-626.

[2] Arrazola PJ, Özel T, Umbrello D, Davies M, Jawahir IS (2013) Recent Advances in Modelling of Metal Machining Processes. CIRP Annals 62(2):695-718.

[3] Lee S, Hwang J, Shankar MR, Chandrasekar S, Compton WD (2006) Large Strain Deformation Field in Machining. Metallurgical and Materials Transactions A 37(5):1633-1643.

[4] Guo Y, M'Saoubi R, Chandrasekar S (2011) Control of Deformation Levels on Machined Surfaces. CIRP Annals 60(1):137-140.

[5] Hijazi A, Madhavan V (2008) A Novel Ultra-High Speed Camera for Digital Image Processing Applications. Measurement Science and Technology 19(8): $1-11$.

[6] Besnard G, Hild F, Roux S (2006) "Finite-Element” Displacement Fields Analysis from Digital Images: Application to Portevin-Le Châtelier Bands. Experimental Mechanics 46(6):789-803.

[7] Johnson GR, Cook WH (1985) Fracture Characteristics of Three Metals Subjected to Various Strains, Strain Rates, Temperatures and Pressures. Engineering Fracture Mechanics 21(1):31-48.

[8] Outeiro JC, Dias AM, Jawahir IS (2006) On the Effects of Residual Stresses Induced by Coated and Uncoated Cutting Tools with Finite Edge Radii in Turning Operations. CIRP Annals 55(1):111-116.

[9] Zorev NN (1966) Metal Cutting Mechanics, Pergamon Press, Oxford.

[10] Rech J, Arrazola PJ, Claudin C, Courbon C, Pusavec F, et al (2013) Characterisation of Friction and Heat Partition Coefficients at the Tool-Work Material Interface in Cutting. CIRP Annals 62(1):79-82.

[11] Krishna SC, Gangwar NK, Jha AK, Pant B (2013) On the Prediction of Strength from Hardness for Copper Alloys. Journal of Materials 1-6.

[12] Astakhov VP, Shvets S (2004) The Assessment of Plastic Deformation in Metal Cutting. Journal of Materials Processing Technology 146(2):193-202. 